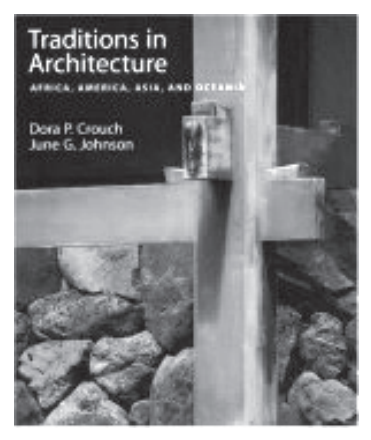

Dora P. Crouch and June G. Johnson

Traditions in Architecture: Africa, America, Asia and Oceania

Oxford: Oxford University Press, 2001

Reviewed by William D. Sapp

Crouch and Johnson have put together an excellent introductory text on traditional, or non-Western, architecture that should delight many readers. Their goal was to provide an introductory text in architectural history that describes non-Western solutions to a wide range of architectural problems common to many societies. They have done a remarkably good job of assembling a variety of examples from a diverse array of cultural traditions, both in time and space. As they state in the Introduction, the current efforts to find practical, durable, and economic solutions to architectural problems that have a minimal impact on our environment are a driving force in the authors' examination of non-Western solutions to problems which confront humans everywhere.

The sources upon which the authors draw are art historical, architectural, ethnographic, and archaeological, thus they encompass a range of scholarly interests and theoretical approaches. One of the highlights of the text is the authors' repetitive use of particular architectural traditions, including Japanese, Indian, Chinese, Nepalese, Peruvian and Mesoamerican, to illustrate various subjects covered in the text. An useful appendix of seven maps identifies the location of each of the examples discussed in the text. In addition the book is profusely illustrated.

The book is divided into five parts, each of which deals with a major theme. The first part, "Multiplicity and Continuity in Tradition," contains two chapters. The first, "Form and Content," examines functional and design continuity over time, focusing on the shrines of evolving and related religious traditions. For examples, the authors compare early Indian cave shrines, Hindu and Jain temples in India, and Buddhist temples in Burma and Japan. The second chapter in this section, "Transfer of Traditional Architectural Knowledge," compares the person-to-person transfer of building traditions found among the Hausa of Nigeria and the Native Americans of the North American Great Plains, with the professional knowledge acquired and transmitted by specialists and guilds in early Indian, Egyptian, and Chinese civilizations.

The second part, "Practical Solutions," is particularly well done and its chapters deal with each of three sub-themes: survival, climate, and material. The range of examples the authors employ is sweeping. For example, irrigation and water control are illustrated by examples from sixth century AD Nepal, Early Dynastic China, and the Empire of 
Chimor in pre-Inka Peru. Food storage, a problem for all agrarian-based societies, is illustrated by the prehistoric city of Mohenjo-Daro, in the Indus Valley, granaries employed by traditional Japanese farmers, and the floating gardens of the Aztecs.

In part three, "Purposes of Traditional Architecture," the authors have three well-organized chapters. One deals with living spaces, from houseboats to palaces, and how they are divided by task and gender. The second, deals with religious architecture, and contains sections on shrines in the home, shrines in the street, and buildings which are specifically built for religious purposes. The third chapter, "Expressions of Power," covers three themes: monumentality, native empire, and the clash of colonial and native culture. Again the range of examples is impressive, including Peru, India, the Caroline Islands, Japan, and Mexico.

Part four, "Planning and Design," is covered in three chapters dealing with land use, building types and the organization of structures. The chapter on land use is particularly well written, with a section on urban planning that compares Mohenjo-Daro, Toledo in Spain, Shrirangam in India, Tang Dynasty Chang'an in China, Nara and Heian in Japan, and the Mesa Verde Cliff Palace in Colorado. The authors' mention of the geometric plan of Chang'an and the use of a text, Rituals of Zhou, to design cities, unfortunately, left me asking for more. However, the opportunity to discuss the mathematical relationships of mandalas and the design of Indian cities was handled much better in the description of Shrirangam.

Part five is entitled "Cultural Values." This section of the book contains six chapters. The first three, "Vernacular and Monumental Combinations," "Symbolism and Ornamentation," and "Architecture and Social Relations," deal well with long-established analytical paradigms in the study of traditional architecture. The next chapter, "Theories of Architecture," offers a newer perspective, dealing with class, gender, ethnicity, and colonial bias and their effect on traditional architecture. The last two chapters, "Architectural Decision Making," and "The Economics of Building," complete the book and bring the reader back to two topics that dominate modern western commercial architecture and building.

As with any book that covers a broad area, some things are necessarily brushed over. The book only tangentially discusses the relationships of mathematics and architecture, although the discussion of Hindu and Jain shrines in Chapter 1, and the use of the mandala in Indian city planning mentioned in Chapter 9 briefly touch on the subject. For example, referring to the Hindu temples of Khajuraho, they write, "The Hindu temples share certain patterns. They were made to look like mountains, appropriate as homes of the gods. Their exteriors consist of three increasingly higher towers, the highest rising above the sanctum." Regarding the interior of the Kandaria Mahadeva temple specifically, the authors state:

Both the inner and outer sanctum are patterned on mandalas. Guardian figures stand at eight significant points around the sanctum. Of the many symbolic references in the temple's architecture, some are invisible in the thickness of the walls, but are known from study of the original mandala. 
Others are evident in the sculptures and the carefully modulated proportions of the plan. Orientalist D. Desai writes, 'The Hindu temple in its developed stage represents man's efforts to symbolizes cosmic order on earth. Its consecrated space, created by precise geometry and calculations, is designed to capture and regulate the cosmic powers in an orderly universe. 'Like the Buddhist stupa, the Hindu temple reconciles multiplicity with unity.

Describing mandala diagrams, Crouch and Johnson explain:

Mandala is an ancient Sanskrit term for 'circle, 'and a mandala is a symbolic diagram that imitates the metaphysical structure of the cosmos in a symmetrical pattern or geometric grid. Some mandalas depict theological understanding in paintings with bright colors and anthropomorphic forms. Others are geometric patterns that guide construction or represent a person's horoscope.

The authors argue that Jain and Hindu religious architecture symbolically encodes messages which reflect basic cosmology and belief. The Hindu temples at Khajuraho encode these messages in a ground plan based on a specific geometry and associated religious icons. They further support their argument with evidence from Buddhist temples in Asuka, Japan and Pagan, Burma.

Like a good introductory text should, this one left me wanting to further explore some of the interesting examples that were presented. The "suggested readings" which accompany each chapter describe topical, in-depth sources that will allow me to do just that. The book is well written and will appeal to a wide academic audience. It presents a variety of disciplinary approaches to data analysis and covers a range of topics with alacrity. The authors accomplished their goal.

\section{About the reviewer}

William D. Sapp is Adjunct Professor at California State University, Northridge. He presented a paper entitled "Design, Construction and Measurement in the Inka Empire" at the Nexus 2000 conference in Ferrara, Italy. 